\title{
Hipospádia e ausência de processo uretral em caprino (Capra hircus) - relato de caso
}

\section{Hypospadias and urethral process absence in caprine (Capra hircus) - case report}

\author{
Antonio Campanha Martinez, ${ }^{*}$ Cassiana Ometto de Abreu, ${ }^{*}$ Fabrício Singaretti de Oliveira, ${ }^{\star}$ Jeffrey Frederico Lui ${ }^{*}$
}

\begin{abstract}
Resumo
O objetivo desse relato é descrever um caso de hipospádia em um caprino, macho, da raça Saanen, de três anos, que foi atendido na Universidade Estadual de Maringá (UEM) - Campus Umuarama, PR. Essa anomalia foi observada durante exame físico do sistema reprodutor, no qual pôde-se evidenciar abertura ectópica do óstio uretral externo no terço médio da rafe peniana, associada à ausência de processo uretral. O animal apresentava os testículos localizados no escroto, prepúcio sem alterações e função espermática normal, demonstrando boa capacidade reprodutiva. A análise cariotípica foi realizada e não se observaram alterações cromossômicas.
\end{abstract}

Palavras-chave: hipospádia, pênis, caprino, alterações reprodutivas.

\begin{abstract}
This paper aimed to describe a case of hypospadias in a three-year old Saanen male goat that was taken at the Maringá State University (UEM) - Umuarama Campus, PR. This anomaly was observed during physical examination of the reproductive system, in which an ectopic opening of the external urethral orifice in the median third of the pennis rafe could be evidenced, besides the absence of the urethral process. The animal presented the testicles located in the scrotum, preputium without alterations and normal spermatic function, showing good reproductive potential. The karyotypic analysis was performed and no chromosomal disorders were noticed.
\end{abstract}

Keywords: hypospadias, pennis, caprine, reproductive disorders.

A hipospádia é uma anomalia congênita da genitália externa, na qual há falha na fusão das pregas urogenitais e desenvolvimento incompleto da uretra peniana (Smith, 1993). Caracteriza-se pela localização ectópica do óstio uretral externo e é a anomalia genital mais comum em homens (Silva Junior et al., 2008), variando em graus, desde um defeito glandular mais comum, como falta de união entre a uretra glandular e peniana, a um relativamente raro, anormalidade perineal e escrotal severa (Marín e Rojas, 2005).

Outras anormalidades associadas com as hipospádias são agenesia renal, defeitos ósseos ou anorretais, hérnias umbilicais, hidrocefalia (Hobson, 1996), e persistência do frênulo prepucial (Galanty et al., 2008). Os cromossomos podem ser utilizados para diferenciar a hipospádia do hermafroditismo verdadeiro (Ader e Hobson, 1978).

Em cães, a ocorrência em machos chega a ser 15 vezes maior que em fêmeas e animais da raça Boston terrier parecem apresentar um fator predisponente. O criptorquidismo foi a segunda anomalia mais comumente diagnosticada, geralmente associada a intersexualidade (Hayes JR e Wilson, 1986).

Subdesenvolvimento peniano, falha na fusão da uretra, prepúcio e escroto e abertura uretral no períneo, além de testículos em posição escrotal e presença de divertículo vesical também já foram observados em cães sem raça definida, sem alteração de cariótipo (Rahal et al, 2001). Em um cão da raça dálmata, foi observada hipospádia com criptorquidismo bilateral e sem alteração cromossômica (Cassata et al., 2008). Deve-se estar atento para não se confundir hipospádia com fístulas uretrais congênitas e/ou duplicação da uretra, em cães (Hedlund e Hosgood, 1996). $\mathrm{Na}$ hipospadia, a uretra se abre ventral e caudalmente ao óstio uretral externo e geralmente existem outras alterações congênitas associadas, como pênis subdesenvolvido, criptorquidismo e anormalidades escrotais, enquanto as fístulas uretrais podem ocorrer isoladas, sem que haja outra alteração no sistema urogenital (Hedlund, 2002).

Hipospádia também foi descrita em bovinos que apresentavam aplasia peniana, criptorquidismo unilateral, bainha

\footnotetext{
* Depto. de Medicina Veterinária - Universidade Estadual de Maringá (UEM) - Campus Umuarama, PR, Brasil. Caixa Postal 65 - CEP $87501-970$ - Umuarama, PR.

** Depto. de Zootecnia - Universidade Estadual Paulista (UNESP), Campus Jaboticabal, SP, Brasil.

Autor para correspondência: singaretti@ig.com.br
} 
prepucial incompleta e óstio uretral externo abrindo-se em escroto bífido ou no períneo ventral (Alam et al., 2005).

Em caprinos, anomalias da genitália externa são incomuns. Entre 1981 e 1990, 21 dentre 1879 animais analisados apresentaram anomalias que os caracterizavam como hermafroditas verdadeiros, pseudohermafroditas machos ou pseudohermafroditas fêmeas, e de 15 animais submetidos à análise de cromossomos, apenas dois apresentaram quimerismo dos cromossomos sexuais $(60, \mathrm{XX} / 60, \mathrm{XY})$ (Yadav et al., 1993).

Dentre as formas de apresentação, a peniana distal representa $70 \%$ dos casos em humanos. O tratamento é estritamente cirúrgico, associado às complicações significativas que o tornam um desafio (Silva Junior et al., 2008). A reconstrução uretral com mucosa oral é um método efetivo para o defeito causado pela hipospádia, com raras complicações pós-operatórias (Kröfl et al., 1998). Podem, ainda, ser utilizadas pele de origem genital ou extragenital (Yavuzer et al., 1998) e matriz acelular de colágeno (Chen et al., 1999) na reparação dessa alteração. Durante a correção cirúrgica da hipospádia, em cães machos, o encurtamento ou amputação do pênis pode ser necessário (Galanty et al., 2008).

Um caprino, macho, da raça Saanen, de três anos, foi conduzido ao Laboratório de Reprodução Animal do Curso de Medicina Veterinária da Universidade Estadual de Maringá (UEM) - Campus Umuarama, PR. Durante o exame físico da genitália externa pôde-se evidenciar abertura ectópica do óstio uretral externo no terço médio da rafe peniana, associada à ausência de processo uretral (Figura 1). 0 animal apresentava os testículos localizados no escroto e prepúcio sem alterações. Colheu-se sêmen, com o uso de eletroejaculador (Duboi ${ }^{\circledR}$ ) e sonda para caprinos. O ejaculado apresentou volume de 1,2 $\mathrm{mL}$, motilidade progressiva de $70 \%$, vigor com valor 3 e concentração espermática de $3,2 \times 10^{9}$ espermatozoides $/ \mathrm{mL}$, sendo considerado normal segundo CBRA (1998).

Realizou-se a análise citogenética para pesquisa de possíveis alterações cromossômicas que poderiam ou não estar associadas à presença da hipospádia. Cerca de $5 \mathrm{~mL}$ de sangue heparinizado foram colhidos da veia jugular externa, resfriado a $12^{\circ} \mathrm{C}$ e encaminhado para o laboratório de Genética Animal da FCAV/UNESP de Jaboticabal, SP. Após o procedimento de cultura de células, segundo Moohread et al. (1960), foram pesquisadas 11 metáfases cromossômicas e verificou-se que o número diplóide era constante para a espécie $(2 n=60)$ e todos os cromossomos estavam de acordo com o padrão, não se encontrando nenhuma anomalia. Concluiu-se tratar de um caso de hipospádia, com o animal apresentando, também, ausência do processo uretral.

O animal reportado aqui apresentava desenvolvimento incompleto da uretra peniana (Smith, 1993), com o óstio

\section{Referências}

ADER, P.L.; HOBSON, H.P. Hypospadia: a review of the veterinary literature and a report of three cases in the dog. J. Am. An. Hosp. Ass. v.14, p.721-727, 1978. uretral externo abrindo-se ectopicamente (Silva Junior et al., 2008) no terço médio da rafe peniana. Essa forma de apresentação peniana observada no animal descrito é a mais comum em humanos, embora a mesma não tenha sido observada em posição distal (Silva Junior et al., 2008) quanto à abertura uretral externa. Classifica-se o caso reportado com hipospádia de grau leve, não havendo anormalidade perineal ou escrotal severa, como descrito na literatura (Marín e Rojas, 2005).

Não foram observados defeitos ósseos ou anorretais, hérnias umbilicais, hidrocefalia (Hobson, 1996), criptorquidismo (Cassata et al., 2008), persistência do frênulo do prepúcio (Galanty et al., 2008), subdesenvolvimento peniano nem abertura uretral no períneo (Rahal et al., 2001). A análise do cariótipo não revelou qualquer alteração como observado em cães (Ader e Hobson, 1978; Rahal et al, 2001) ou em caprinos (Yadav et al., 1993).

Diferentemente do descrito em grandes ruminantes, não foram observados aplasia peniana, criptorquidismo unilateral, bainha prepucial incompleta ou óstio uretral externo abrindo-se em escroto ou períneo (Alam et al., 2005).

Não foi realizada correção cirúrgica da hipospádia, como descrito na literatura (Kröfl et al., 1998; Yavuzer et al., 1998 e Chen et al., 1999) e o animal foi descartado como reprodutor desde então.

O animal do caso reportado era macho, assim como descrito para a maioria dos casos de hipospádia em cães (Hayes JR e Wilson, 1986; Cassata et al., 2008).

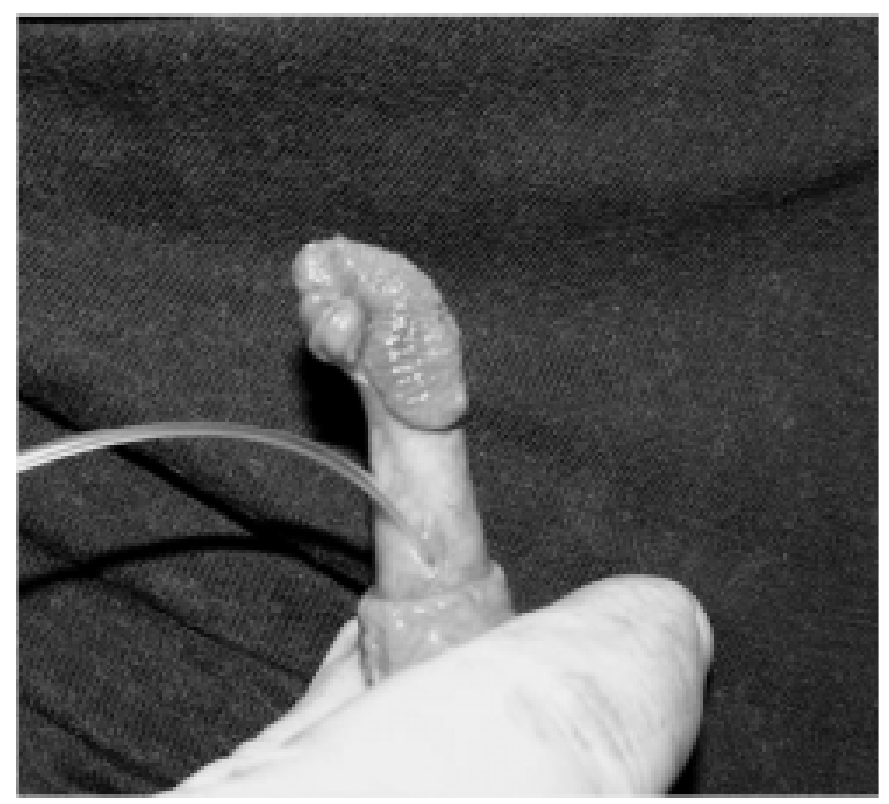

Figura 1: Sonda no óstio uretral externo, localizado na porção média do pênis de caprino com hipospádia. Notar a ausência de processo uretral.

ALAM, M.R., SHIN, S.H.; LEE, H.B.; CHOI, I.H.; KIM, N.S. Hypospadias in three calves: a case report. Vet. Med. Czech. v. 50, p. 506-509, 2005. Disponível em: <http://vetmed.vri.cz/?page=full_papers>. 
CASSATA, R.; IANNUZZI, A.; PARMA, P.; DE LORENZI, L.; PERETTI, V.; PERUCATTI, A.; IANNUZZI, L.; DI MEO, G.P. Clinical, cytogenetic and molecular evaluation in a dog with bilateral cryptorchidism and hypospadias. Cytogen. Gen. Res. v.120, p.140-143, 2008. Disponível em: <http://content.karger.com/ProdukteDB/produkte.asp?Aktion= Ausgabe \&Ausgabe $=235799 \&$ ProduktNr $=224037>$.

CHEN, F.; YOO, J.J.; ATALA, A. Acellular collagem matrix as a possible "off the shelf" biomaterial for urethral repair. Urol. v. 54, p. 406-410, 1999.

COLÉGIO BRASILEIRO DE REPRODUÇÃO ANIMAL-CBRA. Manual para exame andrológico e avaliação de sêmen animal. 2.ed. Belo Horizonte: 1998. 49p.

GALANTY, M.; JURKA, P.; ZIELIÑSKA, P. Surgical treatment of hypospadias. Techniques and results in six dogs. Pol. J. Vet. Sci. v. 11, p. 235-43, 2008.

HAYES JR, H.M.; WILSON, G.P. Hospital incidence of hypospadias in dogs in North America. The Vet. Rec. v. 118, p. 605-607, 1986. Disponível em: < http://veterinaryrecord.bvapublications.com/cgi/ content/abstract/118/22/605>

HEDLUND, C.S. Cirurgia dos Sistemas Reprodutivo e Genital. In: FOSSUM, T. W. (Ed.). Cirurgia de Pequenos Animais. São Paulo: Roca, 2002. p.571-637.

HEDLUND, C.S.; HOSGOOD, G. Moléstia Uretral e Uropatia Obstrutiva. In: BOJRAB, M.J. (Ed.) Mecanismos da moléstia na cirurgia dos pequenos animais. São Paulo: Manole, 1996, p. 617-625.

HOBSON, H.P. Surgical pathophysiology of the penis. In: BOJRAB, M.J. (Ed.) Mecanismos da moléstia na cirurgia dos pequenos animais. São Paulo: Manole, 1996. p. 554-555.
KRÖFL, D.; TUCK, A.; PRLIC, D.; VEREYEN, A. Using buccal mucosa for urethral reconstruction in primary and re-operative surgery. Euro Urol. v. 34, p. 216-20, 1998.

MARÍN, C.R.; ROJAS, T. C. Aspectos etiopatogénicos del paciente con hipospadias / The patient's aspects etiopatogenicos with hypospadias. Revista del Instituto Nacional de Higiene Rafael Rangel. v. 36, p. 30-37, 2005.

MOOHREAD, P.S.; NORWELL, P.C.; MELLMAN, W.J.; BATTIPS, D.M.; HUNGERFORD, D.A. Chromosomes preparations of leucocytes cultured from human peripheral blood. Exp. Cell. Res. v. 20, p .613616, 1960.

RAHAL, S. C.; MOTA, L.S.L.S.; MAMPRIM, M.J.; CIANI, R. B. Perineal hypospadias in a dog. Case report. Int. J. Vet. Med.Vet. on Line. p.12, 2001.

SILVA JÚNIOR, J.L.; ARAÚJO, E.J.; SOUZA, J.A.; CAMACHO, J.; PEREIMA, M.L.; QUARESMA, E.R. Tratamento de hipospádia distal pela técnica de snodgrass. Arq. Catar. Med. v. 37, p. 13-18, 2008.

SMITH, C.W. Surgical diseases of the urethra. In: Slatter, D.H. Textbook of Small Animal Surgery. 2. ed. Philadelphia: WB Saunders. p.1462-1463. 1993.

YADAV, B.; SINGH, C.; KUMAR, P.; TOMER, O.S., YADAV, J.S. Morphological, anatomical and cytogenetical investigations in sexually anomalous goats. Small Rum. Res. v. 11, p. 331-342, 1993.

YAVUZER, R.;BARAN, C.; LATIFOGLU, O.; CENETOGLU, S.; BARAN, N.K. Vascularized double-sided preputial island flap with $\mathrm{W}$ flap glanuloplasty for hypospadias repair. Plast. Rec. Surg. 101, p. 751755, 1998. 